\title{
SÍNDROME INFLAMATÓRIA MULTISSISTÊMICA ASSOCIADA AO SARS-COV-2 EM CRIANÇAS E ADOLESCENTES: UMA SÉRIE DE CASOS
}

\author{
MULTISYSTEM INFLAMMATORY SYNDROME RELATED TO SARS-COV-2 IN \\ CHILDREN AND ADOLESCENTS: A CASE SERIES
}

\author{
Wania Martins Freitas Albuquerque'; Alessandra Ribeiro Ventura Oliveira II*
}

\begin{abstract}
Resumo. A pandemia da COVID-19, causada pelo SARS-CoV-2 e considerada uma crise global de saúde pública, iniciou-se em março de 2020. De acordo com as publicações iniciais, as crianças eram poupadas da COVID-19 grave, mas relatos recentes de crianças desenvolvendo a síndrome inflamatória multissistêmica, associada ao SARS-CoV-2 (MIS-C), começaram a ser publicados. O mecanismo da MIS-C ainda não está claro. É uma doença recente em crianças e adolescentes, mas sabe-se que tem uma apresentação clínica muito semelhante a outras condições inflamatórias pediátricas como a síndrome de Kawasaki, Kawasaki incompleto, síndrome do choque tóxico, sepse bacteriana e síndrome de ativação macrofágica. Neste estudo, os autores objetivam descrever as evidências clínicas e epidemiológicas encontradas sobre essa síndrome e sua associação com SARSCoV-2, através da descrição de 7 casos de pacientes com MIS-C, acompanhados em uma unidade pediátrica. Foram descritos fatores clínicos, achados laboratoriais e tratamento para todos os pacientes e utilizados os critérios para a MIS-C, estabelecidos pela Organização Mundial de Saúde (OMS). Todos os 7 pacientes apresentaram febre, que variou de 4 a 10 dias. 4 pacientes evoluíram com choque hipotensivo. Rush cutâneo, conjuntivite, sintomas respiratórios e edema de extremidades ocorreram em 3 pacientes. Odinofagia esteve presente em dois casos. Entre os sintomas neurológicos, somente 1 paciente evoluiu com confusão mental. O estudo relatou a experiência de uma unidade de pediatria no seguimento de 7 pacientes diagnosticados com MIS-C, sendo 6 pacientes com evidências de infecção anterior por SARS-CoV-2 e sintomatologia diversa. Esses resultados apoiam esta síndrome como uma entidade clínica potencialmente impulsionada por uma resposta imunológica desordenada após infecção por SARS-CoV-2. Dados epidemiológicos e clínicos adicionais podem esclarecer a prevalência da MIS-C e sua associação com SARS-CoV-2.
\end{abstract}

PALAVRAS-CHAVE: Infecções por Coronavírus. Inflamação. Pediatria.

\begin{abstract}
The COVID-19 pandemic, caused by the SARS-CoV-2 virus and considered a global public health crisis, started in March 2020. According to the initial publications, children were spared of serious infection. However, recent reports of children developing the Multisystem inflammatory syndrome (MIS-C) associated with SARS-CoV-2 started being published. The MIS-C mechanism is still unclear. It is a recent disease in children and adolescents, but it is known that its clinical presentation is very similar to other pediatric inflammatory conditions such as Kawasaki Disease (KD), incomplete Kawasaki Disease, toxic shock syndrome, bacterial sepsis and macrophage activation syndrome. This study aims to contribute with clinical and epidemiological evidence on this syndrome and its association with SARS-CoV-2 by reporting 7 cases of patients with MIS-C, assisted at a pediatric unit. Clinical factors, laboratory findings and adopted treatment were described for all patients, and the diagnostic criteria for MIS-C, established by the World Health Organization (WHO), was used. All 7 patients had fever, which ranged from 4 to 10 days. 4 patients developed hypotensive shock. Skin rash, conjunctivitis, respiratory symptoms, and peripheral edema occurred in 3 patients. Odynophagia was present in two cases. Among neurological symptoms, only 1 patient developed mental confusion. The study reported the experience of a pediatric unit in the follow-up of 7 patients diagnosed with MIS-C, 6 of them with evidence of previous SARS-CoV-2 infection and with different symptoms. These results support this syndrome as a clinical entity potentially triggered by immune system disorder after SARS-CoV-2 infection. Additional epidemiological and clinical data may clarify the prevalence of MIS-C and its association with SARS-CoV-2.
\end{abstract}

KEYWORDS: Coronavirus Infections. Inflammation. Pediatrics. 


\section{INTRODUÇÃO}

A doença causada pelo SARSCoV-2 (COVID-19) foi considerada uma crise global de saúde pública, desde março de 2020. Em abril do mesmo ano, aventou-se a possibilidade da ligação de uma síndrome inflamatória multissistêmica, observada no Reino Unido com a síndrome respiratória aguda grave causada pelo SARS-CoV-2. ${ }^{1} \mathrm{Em}$ maio de 2020, foram relatados os casos de 08 crianças inglesas que desenvolveram choque inflamatório, todas com testes positivos para SARS-CoV-2. ${ }^{1,2}$ No entanto, estudos iniciais publicados mostraram que as crianças foram poupadas de COVID-19 grave. ${ }^{2,3,4}$ No mesmo mês, relatos de casos de crianças que apresentaram uma síndrome multissistêmica inflamatória pediátrica(PIMS) potencialmente fatal, também chamada de síndrome inflamatória multissistêmica em crianças (MIS-C), começaram a ser descritos. $5,6,7$

MIS-C é uma doença nova em crianças cujo mecanismo exato ainda não está claro. Mais de $80 \%$ das crianças com MIS-C têm anticorpos IgM e IgG específicos contra SARS-CoV-2, mas apenas cerca de um terço são positivos para a SARS-CoV-2 por RTPCR. ${ }^{8,9,10}$ Esta síndrome tem apresentação clínica similar às observadas em outras condições inflamatórias pediátricas como na síndrome de Kawasaki, Kawasaki incompleto, síndrome do choque

\section{DESCRIÇÃO DOS CASOS}

Este estudo foi aprovado pelo Comitê de Ética e Pesquisa da Fundação de Ensino e Pesquisa em Ciências da Saúde/ FEPECS/ SES/, sob número CAAE: 38712420.8.0000.5553. tóxico, sepse bacteriana e síndrome de ativação macrofágica. ${ }^{11}$ Importante ressaltar que diferente das síndromes citadas acima, observa-se um acometimento maior em crianças com mais de 5 anos de idade, não excluindo as menores, e maior envolvimento cardíaco. ${ }^{11,12,13}$ o primeiro relato de caso de MIS-C, foi publicado nos Estados Unidos em 7 de abril de 2020 e até o final de maio de 2020 já haviam sido descritos mais de 100 casos de crianças e adolescentes. Desde então, vários países começaram a relatar sobre a ocorrência da síndrome inflamatória multissistêmica. ${ }^{11}$

As crianças têm apresentado sinais e sintomas variados, que englobam febre alta persistente, alterações de provas de atividade inflamatória, acometendo um ou mais órgãos (neurológico, cardíaco, gastrointestinal, renal ou respiratório), desde que sejam excluídas causas infecciosas que possam justificar o quadro. Não é obrigatório a confirmação diagnóstica da infecção por SARS-CoV-2, podendo ser considerado apenas exposição ao vírus. ${ }^{11,12,13}$ Desse modo, este estudo objetiva descrever as evidências clínicas e epidemiológicas encontradas sobre a síndrome inflamatória multissistêmica e sua associação com SARS-CoV-2 em crianças e adolescentes, através do seguimento de sete pacientes diagnosticados com MIS-C em uma unidade pediátrica.
Para a descrição dos casos do estudo, foram utilizados os critérios estabelecidos pela Organização Mundial de Saúde (OMS), descritos na Figura $1{ }^{14}$ 
Idade: $0-19$ anos
Febre $>$ ou $=3$ dias

$+$

Laboratório de Inflamação

(Velocidade de Hemossedimentação, Proteína C reativa ou Procalcitonina)

\section{Pelo menos 2 das seguintes alterações:}

- Rash ou conjuntivite bilateral não purulenta ou sinais inflamatórios mucocutâneos (cavidade oral, em mãos ou pés).

- Hipotensão ou choque.

- Achados de disfunção miocárdica, pericardite, valvulite ou alterações coronarianas (ecocardiográficas ou elevação da troponina ou NT-pró-BNP).

- Evidência de coagulopatia (TAP, PTT e D-dímero).

$+$

Sem outra causa microbiológica evidente de inflamação, incluindo sepse bacteriana, síndrome do choque tóxico estafilocócico e estreptocócico

$+$

Evidência de COVID-19 (RT-PCR, antígeno ou sorologia)

OU contato provável com pacientes com COVID-19.

\section{CASO 1}

Paciente sexo feminino, 10 anos de idade, deu entrada no serviço de pediatria com quadro de artralgia em punhos e tornozelos, edema de mãos e pés e febre persistente com duração de 2 dias antes da admissão hospitalar. Evoluiu com surgimento de máculas e pápulas hiperemiadas, difusas pelo corpo, com prurido intenso associado à odinofagia e tosse produtiva. Ao exame físico, apresentava edema bipalpebral, máculas e placas urticariformes difusas pelo corpo.

Obteve melhora da artralgia e prurido após administração de dexclorfeniramina e dipirona. A pressão arterial era $110 \times 90$ $\mathrm{mmHg}$. Alta hospitalar com analgesia e anti-histamínico no mesmo dia. Retornou 24 horas após, com evolução das máculas e pápulas urticariformes para arroxeadas (em face, tronco e membros superiores e inferiores), vesículas em face, febre de $39,3^{\circ} \mathrm{C}$, artralgia em punhos e tornozelos, além de dois episódios eméticos. Realizado tratamento para anafilaxia e coleta de RTPCR para a SARS-COV-2. Laboratório com as seguintes alterações: Hemograma (15500 leucócitos: $94.5 \%$ neutrófilos, $21 \%$ bastões, 1.7\% monócitos, 3.4\% linfócitos; PCR: 307.71 $\mathrm{mg} / \mathrm{L}$ (valor de referência: 0 à $5 \mathrm{mg} / \mathrm{l}$ ), VHS $61 \mathrm{~mm}$ (valor de referência: 0 à $10 \mathrm{~mm} /$ hora), TAP: $65.7 \%$ (valor de referência: 70 à 100\%), TTPA: 41.6 segundos (valor de referência: 24.5 à 37.5 segundos).

Foi prescrito ceftriaxona $4 \mathrm{~g} /$ dia durante 48 horas até resultado da 
hemocultura que foi negativa. Paciente evoluiu com anafilaxia (piora das lesões urticariformes e presença de dispneia), feito adrenalina $0.01 \mathrm{mg} / \mathrm{kg}$ via intramuscular, com boa resposta. O resultado do teste rápido para a SARS-COV-2 (IgM e IgG) foi não reagente, mas a paciente encontrava-se no $5^{\circ}$ dia de doença. O resultado do RT-PCR para a SARS-COV-2, coletado no $3^{\circ}$ dia de doença foi positivo. Radiografia de tórax sem alterações. Diagnosticada MIS-C de acordo com critérios da OMS.

A paciente foi transferida à UTI de hospital terciário para monitorização e tratamento com Imunoglobulina humana endovenosa (2 g/ $\mathrm{kg}$ ), infundida em 24 horas. Os exames da admissão encontramse detalhados na Tabela 1. A equipe médica responsável optou pela não prescrição de ácido acetil salićlico (AAS), visto que a paciente não apresentava todos os critérios para doença de Kawasaki completa.

O resultado do ecocardiograma com doppler foi normal. Após o término da infusão de imunoglobulina, a paciente foi transferida para enfermaria pediátrica, sem intercorrências. Houve melhora completa das lesões cutâneas. Obteve alta hospitalar após 9 dias de internação. Encaminhada para acompanhamento ambulatorial na Reumatologia Pediátrica, onde foi iniciado AAS e suspenso após 2 meses.

TABELA 1: Resultados dos exames laboratoriais realizados na admissão de sete pacientes com diagnóstico de Síndrome Inflamatória Multissistêmica associada ao SARS-CoV-2 (MIS-C) em hospital terciário.

\begin{tabular}{|c|c|c|c|c|c|c|c|}
\hline Características & Caso 1 & Caso 2 & Caso 3 & Caso 4 & Caso 5 & Caso 6 & Caso 7 \\
\hline Leucócitos (x103/uL) & 9,42 & 3.4 & 3.15 & 6.3 & 16.14 & 12.1 & 17.76 \\
\hline Linfócitos (\%) & 9,4 & 8.3 & 48 & 4.6 & 76.8 & 8.5 & 7 \\
\hline Plaquetas (x10³/uL) & 345 & 70 & 199 & 89 & 393 & 160 & 171 \\
\hline Troponina (ng/ml) & 0,1 & Negativo & 0.1 & 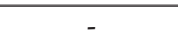 & - & 0.06 & - \\
\hline Proteína C Reativa (mg/dl) & 18,12 & - & 0.07 & 51.82 & 0.043 & 26 & 23 \\
\hline VHS (mm/h) & 50 & - & 39 & - & 25 & 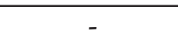 & - \\
\hline TAP (seg) & - & - & - & 15.9 & 11.6 & 13 & - \\
\hline TTPA (seg) & - & 39.2 & - & 33.5 & - & 27.8 & - \\
\hline INR & - & 1.26 & - & 1.34 & 1.01 & - & - \\
\hline D-dímero (ng/ml) & - & 25.838 & - & - & - & - & 10.284 \\
\hline Fibrinogênio (mg/dL) & - & 272 & - & 385 & 139 & 374 & - \\
\hline Albumina (g/dl) & 3,25 & 3.1 & 3.1 & 2.6 & 4.15 & 2.7 & 2 \\
\hline RT-PCR para SARS-CoV -2 & Detectável & Detectáve & $\begin{array}{c}\text { Não } \\
\text { Detectável }\end{array}$ & Detectável & Detectável & $\begin{array}{c}\text { Não } \\
\text { Detectável }\end{array}$ & $\begin{array}{c}\text { Não } \\
\text { Detectável }\end{array}$ \\
\hline Teste Rápido & $\begin{array}{c}\text { Não } \\
\text { Reagente }\end{array}$ & $\begin{array}{l}\text { IgM e IgG } \\
\text { Reagentes }\end{array}$ & $\begin{array}{c}\text { IgM } \\
\text { Reagente }\end{array}$ & $\begin{array}{l}\text { IgM e IgG } \\
\text { Reagentes }\end{array}$ & $\begin{array}{c}\lg M \\
\text { Reagente }\end{array}$ & $\begin{array}{c}\text { IgM } \\
\text { Reagente }\end{array}$ & - \\
\hline
\end{tabular}

\section{CASO 2}

Paciente sexo masculino, 9 anos de idade, com quadro de febre alta há 4 dias, associado à odinofagia, hiporexia, vertigem, dor em região cervical e edema em região occipital direita. Evoluiu 1 dia após com dor abdominal, diarreia, dor testicular e um episódio de epistaxe. Ao exame físico apresentava hipertrofia de tonsila palatina e 
leve hiperemia, linfonodomegalia em região occipital direita, hiperemia e dor local, dor à palpação em testículo esquerdo, hiperemia discreta e presença de varizes locais. Exames de entrada evidenciaram ao hemograma: 3.700 leucócitos: $83.2 \%$ neutrófilos, 2\% bastões, $7.8 \%$ monócitos, $5.1 \%$ linfócitos, 90 mil plaquetas; VHS: $52 \mathrm{~mm} /$ hora (valor de referência: 0 à $10 \mathrm{~mm} /$ hora) e PCR: 66.61 $\mathrm{mg} / \mathrm{L}$ (valor de referência: 0 à $5 \mathrm{mg} / \mathrm{l}$ ). Devido à suspeita inicial de linfadenite, optou-se por iniciar ampicilina + sulbactam $200 \mathrm{mg} / \mathrm{kg} / \mathrm{dia}$.

No terceiro dia de internação, paciente evoluiu com prurido corporal intenso, hiperemia ocular bilateral não supurativa, língua em framboesa, edema labial e hiperemia local intensa, pavilhão auricular direito edemaciado e hiperemiado, abdome com dor à palpação difusa, mas sem sinais de irritação peritoneal, além de persistência de

\section{CASO 3}

Paciente sexo feminino, 17 meses de idade, com quadro de febre alta há 6 dias, associado à coriza hialina, congestão nasal e hiporexia. Há dois dias da admissão evoluiu com vômitos, oligúria e aparecimento de exantema micropapular difuso, não associado a prurido. Ao exame físico encontrava-se em regular estado geral, prostrada, desidratada $(2+/ 4+)$, com hiperemia de orofaringe, fissuras labiais e exantema micropapular difuso, sem presença de urticária. Realizado RT-PCR. Teste rápido para a SARS-COV-2: IGM positivo. Laboratório com as seguintes alterações: Hemograma (10.3 g/dL hemoglobina, 24.6 pg HCM, 32.2 g/dL CHCM, 7.100 leucócitos: 49\% neutrófilos, $7 \%$ bastões, 5\% monócitos, 38\% linfócitos; VHS 30 mm (valor de referência: 0 à 10 mm/hora), TAP: 138.4\% (valor de referência: 70 à 120\%), fibrinogênio: $188 \mathrm{mg} / \mathrm{dL}$ (valor de linfonodomegalia cervical direita, com dor à palpação local. Solicitado teste rápido para a SARS-COV-2 positivo (IGM e IGG) e RT-PCR detectável para a SARS-COV-2. Diagnosticado MIS-C de acordo com critérios da OMS e iniciado imunoglobulina humana endovenosa ( $2 \mathrm{~g} / \mathrm{kg})$. Optado por não iniciar AAS, devido à plaquetopenia e epistaxe recente.

Transferido para UTI de hospital terciário, para seguimento do tratamento. Na admissão na UTI foi evidenciada alteração importante no D-dímero e optado por iniciar enoxaparina. Os exames encontram-se detalhados na Tabela 1. Ecocardiograma sem alterações. $O$ paciente evoluiu bem e recebeu alta em uso de enoxaparina $2 \mathrm{mg} /$ $\mathrm{kg} /$ dia até normalização do D-dímero e AAS. Encaminhado para seguimento ambulatorial na reumatologia pediátrica, onde permaneceu por dois meses.

referência: 220 à $496 \mathrm{mg} / \mathrm{dL})$, TGO: $110 \mathrm{U} / \mathrm{L}$ (valor de referência: 15 à $37 \mathrm{U} / \mathrm{L}$ ).

A paciente evoluiu com instabilidade hemodinâmica no período noturno, com tempo de enchimento capilar lentificado, de 4 segundos, rebaixamento de fígado (3 $\mathrm{cm}$ do rebordo costal), ritmo de galope, taquipnéia, mantendo saturação de $\mathrm{O} 2$ em ar ambiente a $95 \%$ e edema bipalpebral. PA $=87 \times 55 \mathrm{mmHg}$. Iniciado droga vasoativa (dobutamina $10 \mathrm{mcg} / \mathrm{kg} / \mathrm{min}$ ), ampicilina e sulbactan $200 \mathrm{mg} / \mathrm{kg} / \mathrm{dia}$ e imunoglobulina humana endovenosa (2 $\mathrm{g} / \mathrm{Kg})$, devido à suspeita de MIS-C. Devido à gravidade do caso, a paciente foi transferida para UTI em hospital terciário no mesmo dia. Os exames da admissão na UTI encontram-se detalhados na Tabela 1. Mantida infusão de imunoglobulina por 2 dias e iniciado metilprednisolona 1 
$\mathrm{mg} / \mathrm{kg} /$ dose. A paciente evoluiu bem com o tratamento. Ecocardiograma normal e RT-PCR não detectável para a SARS-COV-2. Diagnosticada com MIS-C por apresentar

\section{CASO 4}

Paciente sexo masculino, 12 anos de idade, com quadro de febre alta diária, iniciada há 5 dias, associado a vários episódios de evacuações líquidas, sem sangue, muco ou pus, acompanhada de dor abdominal de moderada intensidade, mialgia e com piora importante há 3 dias da admissão. Negava outros sintomas, inclusive respiratórios. Relato de contato com familiar positivo para COVID-19. Realizado expansão volêmica com soro fisiológico $0.9 \%$ e realizado teste rápido para a SARS-COV-2: não detectável. No dia posterior, evoluiu com choque hipovolêmico. Prescrito ceftriaxona $4 \mathrm{~g} /$ dia por 24 horas, até resultado da hemocultura, que foi negativo.

Evoluiu com dor abdominal intensa, incluindo dor à descompressão brusca, sendo solicitada avaliação da cirurgia geral, a qual descartou abdome agudo cirúrgico. Prescrito analgesia com morfina, evoluindo com melhora do desconforto abdominal. O paciente manteve-se hipotenso, sendo iniciada adrenalina e hidrocortisona com boa resposta. Evoluiu com insuficiência respiratória aguda grave, realizada intubação

\section{CASO 5}

Paciente sexo masculino, 10 meses de idade, há 05 dias com quadro de febre associada a irritabilidade, otalgia presumida e um episódio de diarreia com presença de rajas de sangue. Foi tratado com amoxicilina + clavulanato e ibuprofeno por orientação critérios de acordo com a OMS e optado por iniciar AAS. Encaminhada para seguimento ambulatorial na reumatologia pediátrica, onde permaneceu por dois meses.

orotraqueal e transferência para UTI em hospital terciário. A radiografia de tórax foi normal.

Para transferência do paciente, foi solicitado teste rápido para a SARS-COV-2: positivo IgM e IgG. Durante a internação na UTI, foi realizado RT-PCR: detectável para SARS-COV-2, além dos exames da admissão detalhados na TABELA 1. O paciente foi diagnosticado com MIS-C por apresentar critérios deacordo coma OMS. Iniciado infusão de imunoglobulina humana endovenosa (2 g/kg). Evidenciada alteração importante de D-dímero, sendo necessário iniciar enoxaparina e mantida até a normalização. Ecocardiograma demonstrou insuficiência mitral de grau discreto e insuficiência aórtica mínima.

O paciente evoluiu bem e recebeu alta em uso de enoxaparina $2 \mathrm{mg} / \mathrm{kg} / \mathrm{dia}$ até normalização do D-dímero, AAS e seguimento ambulatorial na reumatologia pediátrica. O ecocardiograma de seguimento foi normal e um mês após foi suspenso o AAS, quando recebeu alta ambulatorial.

médica durante 4 dias, sem regressão da febre, evoluindo logo após com tosse seca e edema palpebral bilateral, mais evidente à esquerda, e de extremidades, quando optou por procurar novamente o serviço. Realizados exames laboratoriais, teste rápido e RT-PCR 
para SARS-COV-2, que evidenciou IgM positivo e detectável respectivamente. Como a criança estava apresentando febre persistente e devido a sintomatologia, foi diagnosticado MIS-C, iniciado a infusão de imunoglobulina ( $2 \mathrm{~g} / \mathrm{Kg}$ ) e transferido para o serviço de reumatologia pediátrica de hospital terciário devido a potencial de gravidade. Os

\section{CASO 6}

Paciente sexo feminino, 6 anos de idade, com quadro de cefaléia de forte intensidade, não controlada com uso de analgésico há 5 dias. Evoluiu após 2 dias com febre persistente, vômitos, diarreia, dor abdominal, prostração e hiporexia. Acompanhava o quadro, tosse seca esporádica. Ao exame físico encontravase hipocorada, desidratada (+/4+), discreta hiperemia conjuntival bilateral não purulenta, língua em framboesa e linfonodo submandibular esquerdo aumentado. Solicitado teste rápido para a SARS-COV-2: positivo $\lg M \quad e$ RT-PCR: não detectável.

Laboratório com as seguintes alterações: Hemograma (10.0 hemoglobinas 12.100 leucócitos: $84 \%$ neutrófilos, 10\% bastões, 3.0\% monócitos, $7.0 \%$ linfócitos); atividade de protrombina $69.4 \%$ (valor de referência: 70-120\%); DHL 356 U/L (valor de referência: 81-234 U/L). A paciente evoluiu exames da admissão encontram-se detalhados na Tabela 1. O Ecocardiograma foi normal.

O paciente evoluiu bem e recebeu alta em uso de AAS e seguimento ambulatorial na reumatologia pediátrica. O ecocardiograma de seguimento foi normal. O AAS foi suspenso dois meses após, quando recebeu alta ambulatorial.

com piora do quadro, instabilidade hemodinâmica, tempo de enchimento capilar lentificado, taquicardia, turgência jugular, taquipnéia, saturação de $\mathrm{O} 2$ acima de $94 \%$ em ar ambiente, hipotensa. Iniciado droga vasoativa (adrenalina $0.1 \mathrm{mcg} /$ $\mathrm{Kg} / \mathrm{h})$, ceftriaxona $(50 \mathrm{mg} / \mathrm{Kg} / \mathrm{dia}$, até o resultado da hemocultura que foi negativo) e imunoglobulina humana endovenosa (2 $\mathrm{g} / \mathrm{Kg}$ ), devido ao diagnóstico de MIS-C. Foi transferida para a UTI em hospital terciário no mesmo dia. Os exames da admissão encontram-se detalhados na Tabela 1.

Mantida infusão de imunoglobulina por 2 dias e iniciados metilprednisolona 1 $\mathrm{mg} / \mathrm{kg} /$ dose e clexane, com boa resposta. Ecocardiograma foi normal. Foi diagnosticada com MIS-C por apresentar os critérios de acordo com a OMS. Recebeu alta com AAS, clexane e seguimento ambulatorial na reumatologia pediátrica durante dois meses.

\section{CASO 7}

Paciente, 5 anos, sexo masculino, com quadro de febre alta, prostração e nodulação em região cervical esquerda. Foi prescrito amoxicilina + clavulanato durante 07 dias. No dia seguinte evoluiu com petéquias disseminadas em todo o corpo, sem prurido, seguido de tosse seca esporádica, optando por retornar ao serviço, onde foi suspenso 
antibiótico e orientado uso de sintomáticos. No dia posterior persistiu com febre alta, não responsiva à antitérmicos, evoluiu com tosse produtiva e iniciado salbutamol spray oral. No dia seguinte, a paciente evoluiu com prostração, dor abdominal de forte intensidade, associado a vômitos e oligúria, quando deu entrada no serviço de pediatria pela terceira vez. Ao exame físico, o paciente encontrava-se em mal estado geral, hipocorado, desidratado $(3+/ 4+)$, taquicárdico, com tempo de enchimento capilar lentificado, 5 segundos, presença de linfonodo cervical posterior de aproximadamente $2 \mathrm{~cm}$, móvel e indolor, fissura e edema em lábios, além de petéquias em mãos e região cervical à direita.

A $\mathrm{PA}=80 \times 60 \mathrm{mmHg}$. Realizado medidas iniciais, solicitado exames laboratoriais e coletado RT-PCR para a SARS-COV-2: não detectável. Laboratório com as seguintes alterações: Hemograma (10.8 hemoglobina, 8.600 leucócitos: 85\% neutrófilos, metamielócitos 4\%, 55\% bastões, 7.0\% linfócitos); atividade de protrombina 46.2\% (valor de referência: 70-120\%); tempo de protrombina 17.4 segundos (valor de referência: 10-14 segundos); INR 1.5 (valor de referência: 0.00-1.20); Tempo de tromboplastina parcial ativado 43.5 segundos (valor de referência: 24.5-37.5 segundos).

Após duas fases de expansão com SF $0.9 \%$, paciente evoluiu com exantema disseminado por todo o corpo e também hiperemia conjuntival bilateral. Diagnosticado MIS-C e iniciado imunoglobulina humana endovenosa $(2 \mathrm{~g} / \mathrm{kg})$, pois apresentou critérios de acordo com a OMS. O paciente manteve-se instável durante toda a noite e no dia seguinte evoluiu com sinais de insuficiência cardíaca (turgência jugular, hepatomegalia, creptações em bases pulmonares, ritmo cardíaco irregular, em galope e edema de face e extremidades importante). Colocado em máscara não reinalante $8 \mathrm{~L} / \mathrm{min}$ e iniciado dobutamina (5 $\mathrm{mcg} / \mathrm{kg} /$ minuto), com necessidade de aumento de dose durante o decorrer do dia e metilprednisolona ( $2 \mathrm{mg} / \mathrm{kg} / \mathrm{dia}$, após contato com equipe de reumatologia pediátrica). Transferido para UTI em hospital terciário, onde permaneceu durante 05 dias. Os exames da admissão encontram-se detalhados na Tabela 1.

Eecocardiograma evidenciou insuficiência mitral discreta, derrame pericárdico laminar e hipertrofia concêntrica de grau discreto do ventrículo esquerdo. Recebeu alta em uso de AAS e seguimento ambulatorial na reumatologia pediátrica. O AAS foi suspenso dois meses, quando recebeu alta ambulatorial.

\section{DISCUSSÃO}

Neste estudo, foram incluídos sete pacientes pediátricos com diferentes características clínicas e resultados. Foram 4 pacientes do sexo masculino e 3 do sexo feminino. Os dados do Brasil revelam maior ocorrência na faixa etária de 0 a 4 anos de idade $(38,4 \%){ }^{12,13}$ De acordo com o Centro de Controle e Prevenção de Doenças estadunidense (CDC), a proporção de pacientes pediátricos acometidos pela
MIS-C é ligeiramente maior entre os latinos e corresponde a cerca de $70 \%$ do total dos acometidos nesta faixa etária. ${ }^{14,15}$

Com relação aos sintomas, todos os sete pacientes apresentaram febre, que variou de 4 a 10 dias. Dos 7 pacientes, 4 evoluíram com choque hipotensivo. Rush cutâneo, a conjuntivite, os sintomas respiratórios e o edema de extremidades apareceram em 3 pacientes. A odinofagia esteve presente em 
dois casos. Entre sintomas neurológicos, somente o paciente 4 evoluiu com confusão mental. Os sintomas apresentados pelos sete pacientes são descritos na Tabela 2.

O surgimento do SARS-COV-2 em humanos e a pandemia resultante de COVID-19 é uma crise de saúde global ainda em andamento. ${ }^{15}$ Uma das características desta doença na população pediátrica é seu curso relativamente benigno. ${ }^{16,17}$ Mesmo na presença de índices altos de RNA viral nasofaríngeo em crianças infectadas com SARS-COV-2, o que demonstra um estado permissivo para replicação viral. ${ }^{18} \mathrm{O}$ número de relatos mundiais de crianças com MIS-C, que, além de febre persistente, diarreia e erupção cutânea variável, conjuntivite e edema de extremidades, parece frequentemente estar associado a graves doenças incluindo choque e disfunção miocárdica, tem aumentado. ${ }^{19,20,21}$

Em recente análise retrospectiva de 141 prontuários de crianças que apresentaram COVID-19, as complicações neurológicas foram menos comumente vistas, apenas 7 (5\%). Entre as sete crianças com complicações neurológicas, convulsões e fraqueza neuromuscular foram os sintomas comuns observados. $^{22}$

A série de casos deste estudo apoia essa síndrome como uma entidade clínica potencialmente impulsionada por uma resposta imunológica desordenada, após a infecção por SARS-COV-2. A evidência de infecção anterior inclui teste de anticorpos positivo para anticorpos IgG e IgM contra SARS-COV-2 em todos os pacientes, exceto para o paciente 1 e PCRs nasofaríngeos positivos em 4 pacientes. Apesar da quantidade de sintomas e sinais que se assemelham às características da doença de Kawasaki, existem várias características que podem diferenciar essa síndrome, incluindo disfunção cardíaca proeminente com liberação de troponina e VHS extremamente elevados; enteropatia frequente e grave; ${ }^{23,24}$ trombocitopenia relativa conforme observado emestadoshiperinflamatórios, como síndrome de ativação macrofágica e síndrome do choque da doença de Kawasaki. ${ }^{15}$ Para alguns pacientes, febre e sintomas gastrointestinais precederam o desenvolvimento de outras características clínicas "clássicas" da doença de Kawasaki, incluindo erupção cutânea, conjuntivite, alterações da membrana mucosa e edema de extremidade, que estavam presentes de forma variável nos pacientes do estudo.

Os pacientes, participantes do estudo, receberam terapias que têm sido usadas com sucesso para a condução da MIS-C, incluindo imunoglobulina endovenosa e metilprednisolona. Na maioria dos pacientes, isso foi altamente eficaz na redução da

TABELA 2: Descrição dos sinais e sintomas apresentados por 7 pacientes com diagnóstico de Síndrome Inflamatória Multissistêmica associada ao SARS-CoV-2 (MIS-C)

\begin{tabular}{|c|c|c|c|c|c|c|c|}
\hline Características & Caso 1 & Caso 2 & Caso 3 & Caso 4 & Caso 5 & Caso 6 & Caso 7 \\
\hline Febre & Sim & Sim & Sim & Sim & Sim & Sim & Sim \\
\hline Choque & Não & Não & Sim & Sim & Não & Sim & Sim \\
\hline Hipotensão & Não & Não & Sim & Sim & Não & Sim & Sim \\
\hline Rash & Sim & Não & Sim & Não & Não & Não & Sim \\
\hline Conjuntivite & Não & Sim & Não & Não & Não & Sim & Sim \\
\hline Sintomas respiratórios & Não & Não & Não & Não & Sim & Sim & Sim \\
\hline Sintomas Gastrointestinais & Sim & Sim & Sim & Sim & Sim & Sim & Sim \\
\hline Confusão mental & Não & Não & Não & Sim & Não & Não & Não \\
\hline Odinofagia & Sim & Sim & Não & Não & Não & Não & Não \\
\hline Edema de extremidades & Sim & Não & Não & Não & Sim & Não & Sim \\
\hline
\end{tabular}


inflamação sistêmica, conforme evidenciado pela resolução da febre, com melhora da função cardíaca ao longo de alguns dias.

O tratamento para a MIS-C não está estabelecido completamente. Observa-se que a maioria dos pacientes acometidos, recuperase com suporte ventilatório e hemodinâmico, uso de imunoglobulina venosa e/ou glicocorticóides. ${ }^{25,26} \mathrm{Em}$ recente estudo de coorte observacional internacional de dados clínicos e de resultados relativos à suspeita de MIS-C para avaliar a imunoglobulina intravenosa (IVIG) como referência, em comparação com IVIG mais glicocorticóides e glicocorticóides isoladamente, não foram encontradas evidências de que a recuperação da MIS-C diferiu após o tratamento primário com IVIG sozinha, IVIG mais glicocorticóides ou apenas glicocorticóides. ${ }^{27}$
O tempo de internação hospitalar variou de 4 a 12 dias. Apenas o paciente 4 necessitou suporte ventilatório avançado. Todos receberam alta hospitalar recuperados. A idade, gênero e as características clínicas de cada paciente são descritas na Tabela 3.

Quanto às limitações, o paciente 2 ficou sem dosagem inicial de proteínas de fase inflamatória. Dois pacientes apenas obtiveram a dosagem do D-dímero, que se apresentou elevado, evidenciando coagulopatia. O trabalho da equipe multidisciplinar foi indispensável para $\mathrm{o}$ atendimento e acompanhamento dos sete pacientes diagnosticados com MIS-C. O suporte terapêutico oportuno foi indispensável para uma evolução satisfatória do quadro clínico de cada paciente.

TABELA3: Descrição das características de 7 pacientes com diagnóstico de Síndrome Inflamatória Multissistêmica associada ao SARS-CoV-2 (MIS-C)

\begin{tabular}{cccccccc}
\hline Características & Caso 1 & Caso 2 & Caso 3 & Caso 4 & Caso 5 & Caso 6 & Caso 7 \\
\hline Idade & 10 anos & 9 anos & 15 meses & 12 anos & 10 anos & 6 anos & 5 anos \\
\hline Gênero & Feminino & Masculino & Feminino & Masculino Masculino & Feminino Masculino \\
\hline Duração de Doença & 4 meses & 5 meses & 3 meses & 2 meses & 3 meses & 2 meses & 4 meses \\
\hline \hline Duração da febre & 8 dias & 9 dias & 7 dias & 8 dias & 10 dias & 4 dias & 7 dias \\
\hline \hline Tempo de internação hospitalar & 9 dias & 8 dias & 4 dias & 12 dias & 8 dias & 5 dias & 10 dias \\
\hline Dias de VNI* & 0 & 0 & 0 & 0 & 0 & 0 & 0 \\
\hline Dias de VMI* & 0 & 0 & 0 & 4 & 0 & 0 & 0 \\
\hline Alta hospitalar & Sim & Sim & Sim & Sim & Sim & Sim & Sim \\
\hline Morte & Não & Não & Não & Não & Não & Não & Não \\
\hline Recuperação & Sim & Sim & Sim & Sim & Sim & Sim & Sim \\
\hline \hline
\end{tabular}

\section{CONSIDERAÇÕES FINAIS}

Pacientes pediátricos previamente saudáveis podem evoluir para um quadro de Síndrome Inflamatória Multissistêmica associada ao SARS-CoV-2, apresentar sintomas graves e necessitar de cuidados terapêuticos intensivos, embora a COVID-19 apresente menor gravidade nesta faixa etária.
Portanto, é fundamental conhecer a clínica e a epidemiologia da Síndrome Inflamatória Multissistêmica associada à COVID-19 parapermitir maior agilidade no diagnóstico, tratamento precoce e contribuir para o enfrentamento da doença. 


\section{REFERÊNCIAS BIBLIOGRÁFICAS}

1. Luz A, Niering DB, Silva SL. Caderneta de Saúde da Pessoa Idosa: conscientização dos profissionais nas Unidades Básicas de Saúde no município de Joinville. 2018. Available at: <http://joinville. ifsc.edu.br/ bibliotecajoi/arquivos/monografias/ saudeidoso2018/197406.pdf> Access on: Aug. 03rd 2020.

2. Reis SAA. A importância da vacinação no idoso. 2015. Available at: < https://core.ac.uk/download/ pdf/43589553.pdf> Access on: Oct. 20th 2020.

3. Santos RR, Côrrea MA. Determinantes que dificultam a adesão da vacina antigripal por idosos. 2015. Available at: < http://www.ipec-pa.com.br/ aluno/arquivos/tcc/correa_santos.pdf> Access on: Aug. 22nd 2020.

4. Brasil. Informe Técnico. $22^{\mathrm{a}}$ Campanha Nacional de Vacinação contra a influenza. 2020. Available at: < https://sbim.org.br/images/files/notas-tecnicas/ informe-tecnico-ms-campanha-influenza-2020-final. pdf > Access on: Aug. 10th 2020.

5. Monteles MS, Aragão FBA, Pereira JFS, Gomes FCS. Fatores de não adesão dos idosos à vacina contra influenza: uma revisão bibliográfica. Uningá Review. 2017; 30(3): 76-82. 1.Painel WHO COVID-19. Disponível online: https://covid19.who.int/ (acessado em 08 de julho de 2021).

2.Gupta, S., Malhotra, N., Gupta, N., Agrawal, S., Ish, P. The curious case of coronavirus disease 2019 (COVID-19) in children. J Pediatr 2020; 222(1):258-59.

3.Brodin, P. Why is COVID-19 so light in children? Acta Paediatr 2020;109(1):108283.

4. Rawat, M., Chandrasekharan, P., Hicar, M.D., Lakshminrusimha, S. COVID-19 in newborns and infants - low risk of serious illness: silver lining or dark cloud? J Perinatol 2020; 37(1):845-49.

5. Whittaker, E., Bamford, A., Kenny, J., Kaforou, M., Jones, C.E., Shah, P., et al. Clinical features of 58 children with pediatric multisystem inflammatory syndrome temporarily associated with SARS-CoV-2. JAMA J. Am Med Assoc 2020; 324(1):259-69.

6. Verdoni, L., Mazza, A., Gervasoni, A., Martelli, L., Ruggeri, M., Ciuffreda, M., et al. A severe Kawasakilike desease outbreak in the italian epicenter of the SARS-CoV-2: An observational cohort study. Lancet 2020; 395(1):1771-78.

7. Belhadjer, Z., Meot, M., Bajolle, F., Khraiche, D., Legendre, A., Abakka, S., et al. Acute Heart Failure in Multisystem Inflammatory Syndrome in Children In the Context of the Global SARS-CoV-2 Pandemic. Circulation 2020; 142(1):429-36.

8. Nakra, N.A., Blumberg, D.A., Herrera-Guerra, A., Lakshminrusimha, S. Multisystem Inflammatory Syndrome in Children (MIS-C) after SARS-CoV-2 infection: review of clinical presentation, hypothetical pathogenesis and proposed management. Children 2020; 7(1):69-70.

9. Godfred-Cato, S., Tsang, C.A., Giovanni, J., Abrams, J., Oster, M.E., Lee, E.H., et al. Multisystem Inflammatory Syndrome in Infants above 12 months of Age, United States, May 2020 - January 2021. Pediatric Infect Dis J 2021; 40(1):601-05.

10. Godfred-Cato, S., Bryant, B., Leung, J., Oster, M.E., Conklin, L., Abrams, J., et al. Multisystem Inflammatory Syndrome Associated with COVID-19, United States, 2020. MMWR. Morb Mortal Wkly Rep 2020; 69(1):1074-80.

11. Sociedade Brasileira de Reumatologia (SBR). Nota de alerta sobre síndrome inflamatória multissistêmica em crianças e adolescentes associada à COVID-19. São Paulo (SP): SBR; 2020.

12. Sociedade Brasileira de Pediatria(SBP). Documento cientifico: síndrome inflamatória multissistêmica em crianças e adolescentes provavelmente associada à COVID-19: uma apresentação aguda, grave e potencialmente fatal. Rio de Janeiro (RJ): SBP; 2020. 
13. Campos, L.R., Cardoso, T.M., Martinez, J.C., Almeida, R.G., Fonseca, A.R, Sztajnbok, F.R. Síndrome inflamatória multissistêmica pediátrica (MIS-C) temporalmente associado ao COVID-19. Rev Resid. Ped 2020;10(2):348-56.

14. World Health Organization (WHO). Multisystem inflammatory syndrome in children and adolescents temporally related to COVID-19. Geneva: WHO; 2020.

15. Viral Disease Division. National Center for Immunization and Respiratory Diseases (NCIRD). Centers for Disease Control and Prevention. Multisystem Inflammatory Syndrome in Children (MIS-C) Associated with Coronavirus Disease 2019 (COVID-19); 2021.

16. Estrela, F.M., Soares, C.F., Cruz, M.A., Silva, A.F., Santos, J.R., Moreira, T.M., et al. Pandemia da Covid 19: refletindo as vulnerabilidades a luz do gênero, raça e classe. Ciênc Saúde Coletiva 2020; 25(9):343136.

17. Dong, Y., Mo, X., Hu, Y., Qi, X., Jiang, F., Jiang, Z., et al. Epidemiology of COVID-19 among children in China. Pediatrics 2020; 145(1): e20200702.

18. Centers for Disease Control (CDC) COVID-19 Response Team. Coronavirus disease 2019 in children-United States, February 12-April 2, 2020. Morbid Mortal Wkly Rep 2020; 69(14):422-26.

19. Jones, T.C, Muhlemann, B., Veith, T., Biele, G., Zuchowisk, M., Hofmann, J., et al. An analysis of SARS-CoV-2 viral load by patient age. 2021. Available at: https://virologie-ccm.charite.de/fileadmin/user_ upload/ pdf. Accessed 12 May 2021.

20. Riphagen, S., Gomez, X., Gonzalez-Martinez, C., Wilkinson, N., Theocharis, P. Hyperinflammatory shock in children during COVID-19 pandemic. Lancet
2020; 395(1):1607-08.

21. Carvalho, H.T., Cília, R., Thomazi, L., J.R., Carpi, M.F. Diagnóstico e tratamento da síndrome inflamatória multissistêmica temporalmente relacionada à COVID-19 em adolescente: relato de caso. Rev Resid. Ped.; 2021(1); 491-94.

22. Oliveira, A.R., Pádua, C.M., Alves, M.C., Silva, G.N., Paula, F.N., Albuquerque, W.M., et al. Manifestações cutâneas em paciente com síndrome inflamatória multissistêmica pediátrica temporariamente associada ao SARSCoV-2: relato de caso. Rev Resid. Ped. 2021;11(1):350-58.

23. Saba, S., Raza, M., Samina, J., Sidra, M. Clinical features and outcome of COVID-19 positive children from a tertiary healthcare hospital in Karachi. J Med Virol 2021; 10(1):5888-97.

24. Yun, S.H., Yang, N.R., Park, S.A. Associated symptoms of Kawasaki disease. Korean Circ J 2011; 41(1):394-98.

25. Baker, A.L., Lu, M., Minich, L.L. Pediatric Heart Network Investigators. Associated symptoms in the ten days before diagnosis of Kawasaki disease. J Pediatr 2009; 154(1):592-595.e2.

26. Matsubara, D., Kauffman, H.L., Wang, Y., Calderon-Anyosa, R., Nadaraj, S., Elias, M.D., et al. Echocardiographic findings in pediatric multisystem inflammatory syndrome associated with COVID-19 in the United States. J Am Coll Cardiol 2020;76(17):194761.

27. Andrew, J.M, Ortensia, V., Harsita, P., Eleanor, G.S., Priyen, S., Clare, W., et al. Treatment of Multisystem Inflammatory Syndrome in Children. N Engl J Med 2021; 385(1): 11-22. 